\title{
Testicular angiogenic activity in response to food restriction in rabbits
}

\author{
M Carvalho, L Mateus ${ }^{1}$, F Afonso ${ }^{1}$, S Van Harten ${ }^{2}$, L Alfaro Cardoso², D A Redmer ${ }^{3}$ \\ and G Ferreira-Dias ${ }^{1}$
}

Faculty of Sciences, University of Lisbon, Lisbon, Portugal, ${ }^{1}$ CIISA, Faculty of Veterinary Medicine, Technical University of Lisbon (UTL), Lisbon, Portugal, ${ }^{2}$ Tropical Research Institute (IICT), Lisbon, Portugal and ${ }^{3}$ Department of Animal Sciences, North Dakota State University, Fargo, North Dakota, USA

Correspondence should be addressed to G Ferreira-Dias at CIISA, Faculdade de Medicina Veterinária, Avenida da Universidade Técnica, 1300-477 Lisboa, Portugal; Email: gmlfdias@fmv.utl.pt

\begin{abstract}
The objective of this study was to evaluate the effects of two different levels of food restriction on testicular angiogenic activity, microvascularization, tissue growth, and regression, using the rabbit as a study model. The rabbits (Oryctolagus cuniculus cuniculus) were randomly assigned to a control group $(A, n=5)$, fed ad libitum, and to groups $B(n=5)$ and $C(n=5)$, with two different levels of food restriction. Food restriction was responsible for a $21.2 \%$ decrease in body weight in group $B$ and $34.7 \%$ in group $C$. Testis explants were cultured for $\mathbf{2 4} \mathrm{h}$ and conditioned media were tested for their ability to stimulate mitogenesis of bovine aortic endothelial cells (BAEC). There was an increase in testicular microvascular area and mitogenesis of BAEC in group $C$ rabbits. Despite no change in testicular DNA concentration among groups, food restriction decreased both RNA and protein compared with control. No treatment differences in the percentage of seminiferous tubules filled with all stages of spermatogenesis (spermatogonia, spermatocytes, and spermatids) and spermatozoa, as well as the area occupied by seminiferous tubules, were observed. Nevertheless, serum testosterone was markedly less in group $C$ compared with groups $A$ and $B$. These results suggest that angiogenesis may play a role in overcoming testicular nutritional impairment in rabbits subjected to food restriction.

Reproduction (2009) 137 509-515
\end{abstract}

\section{Introduction}

Nutrition plays an important role in growth and development of the reproductive system. Animals often exposed to dramatic climatic changes (periodic draughts) inducing food restriction have developed survival tactics that include cessation of energetically costly processes, such as growth and reproduction (Bronson 1999). Food restriction shifts nutrients away from reproductive function toward somatic cell maintenance (McCarter et al. 1985).

Studies in different animal species indicate that dietary restriction can have a positive effect on the delay of several diseases, improving health and extending longevity, specifically reducing both the incidence and the growth of tumors (Birt et al. 1999, Beecken et al. 2001, Mukherjee et al. 2002, 2004). Alterations in the metabolic, neuroendocrine, and apoptotic processes are also observed, in order to assure the individual's survival. However, these changes occur differently in specific organ systems (Mukherjee et al. 2002, Koubova \& Guarente 2003).

Dietary restriction has an effect on testes, leading to a progressive decrease in testicular volume (Thwaites
1995). This decline is more significant as dietary restriction is intensified (Thwaites 1995, Young et al. 2000, Santos et al. 2004). Testicular regression can be mediated by apoptosis, such as in white-footed mice (Young et al. 2000). Mice subjected to food restriction exhibited a decline in testicular and epididymal weights, and reduced serum testosterone levels (Santos et al. 2004). However, in contrast with these findings, rats subjected to a $30 \%$ caloric restriction for 8 weeks showed an increase in testicular weight when compared with unrestricted control animals (Gursoy et al. 2001).

Angiogenesis, the formation of new blood vessels from the pre-existing vasculature, is a process that, in adults, is a relatively infrequent event. Physiological angiogenesis in the adult is mostly restricted to the female reproductive tract during the ovarian/uterine cycle (Reynolds et al. 1992, Augustin et al. 1995, Ferreira-Dias et al. 2006, Roberto da Costa et al. 2007), and to the male reproductive tract during gonadal recrudescence in seasonal breeders (Mayerhofer et al. 1989). However, neovascularization is also present in adult life in conditions such as tissue repair or regeneration during healing of wounds or fractures, or 
in the re-establishment of blood flow, playing an essential role in the transport of oxygen and nutrients (Reynolds et al. 1992, Ishiko et al. 2001). Angiogenesis is regulated through a dynamic balance between the production and release of angiogenic/mitogenic substances or growth factors and by inhibitory or antiangiogenic/anti-mitogenic growth factors (Hudlicka 1984, Folkman \& Klagsburn 1987, Espinosa Cervantes \& Rosado Garcia 2002, Hazzard et al. 2002). Still, there are situations when the body loses control over this process, leading to some pathological situations due to excessive or insufficient blood vessel growth (Reynolds et al. 1992, Chavakis \& Dimmeler 2002).

In mice, dietary restriction seems to reduce the development of brain tumors through a decrease in vascularization and an increase in the apoptotic index with little interference on cellular proliferation (Mukherjee et al. 2002). However, these mechanisms are still not clear (Beecken et al. 2001, Mukherjee et al. 2002). Besides, in adipose tissue, angiogenesis might be responsible for a rebound weight gain after a dietrestricted period, restoring the initial levels (Morimura et al. 2001). In long-day seasonal breeders, such as the hamster, increased angiogenesis and rapid renewal of testicular microvasculature is fundamental for physiologic recrudescence (Mayerhofer et al. 1989). However, in testicular tissue, little is known about the effects of dietary restriction on vascularization and associated mechanisms involved in this process. Therefore, in order to better understand the effects of dietary restriction on testicular function during puberty, the objectives of the present study were to clarify and compare the effects of different levels of undernutrition on testicular angiogenesis capacity, vascularization, tissue growth and regression, and seminiferous tubules function using the rabbit as an animal model. To the best of our knowledge, this is the first published study on the effects of caloric restriction on testicular angiogenesis and development on male rabbit during puberty.

\section{Results}

Food restriction was responsible for a in $21.2 \%$ decrease in body weight in group B and $34.7 \%$ in group C. Testicular weights decreased from control group $A$ and group $B$ to $C$ rabbits (Table $1 ; P<0.05$ ). The percentage of testicular weight over body weight was significantly decreased between control group $\mathrm{A}$ and group $\mathrm{C}$ animals (Table $1 ; P<0.05)$. Testicular histological sections were examined for the assessment of the area occupied by seminiferous tubules as well as the percentage of seminiferous tubules with all stages of spermatogenesis and spermatozoa in the lumen. No significant difference among experimental groups was detected in the percentage of area occupied by seminiferous tubules and in the percentage of tubules that contained all stages of spermatogenesis and spermatozoa in the lumen.
Table 1 Rabbit testicular weights (epididymis not included) and percentage of testicular weight relative to body weight in control group (A) and food-restricted groups (groups B and C).

\begin{tabular}{lcc}
\hline Experimental group & Testicular weight $(\mathrm{g})$ & $\begin{array}{c}\text { \% Testicular } \\
\text { weight/body weight }\end{array}$ \\
\hline A & $3.12^{\mathrm{a}}$ & $0.09^{\mathrm{a}}$ \\
$\mathrm{B}$ & $2.67^{\mathrm{a}}$ & $0.08^{\mathrm{a}, \mathrm{b}}$ \\
C & $1.81^{\mathrm{b}}$ & $0.07^{\mathrm{b}}$ \\
\hline
\end{tabular}

Variables with different superscripts differ significantly (a versus $b$, $P<0.05)$.

Nevertheless, plasma testosterone showed a marked decrease in group $\mathrm{C}$, compared with groups A and B (Fig. 1).

Testicular microvascular area in group $C$ rabbits was increased compared with group B and control group A (Fig. 2). However, the number of testicular blood vessels was the highest in the animals fed ad libitum, when compared with both food-restricted groups (Fig. 3). Nevertheless, when the presence of angiogenic factors in culture media was indirectly assessed by the evaluation of bovine aortic endothelial cells (BAEC) mitogenesis, an increase in cell proliferation was also observed when these cells were incubated in the presence of testicular conditioned media from the experimental rabbits subjected to the highest food restriction (group C), when compared with control group A and group B (Fig. 4). No difference was observed on BAEC proliferation for negative controls (data not presented).

In order to assess testicular growth or regression, DNA, RNA, and protein concentrations were quantified. Despite no change in DNA concentration among groups, RNA concentration decreased in both diet-restricted groups (B and C) compared with rabbits fed ad libitum (Table 2). In addition, protein concentration also decreased significantly in all diet-restricted rabbits. When compared with animals fed ad libitum, protein concentration in rabbit testes significantly decreased in groups B and C (Table 2). Additionally, values for RNA:DNA were also lower in testicular tissue in foodrestricted groups $\mathrm{B}$ and $\mathrm{C}$ (Table 2). Testicular protein:DNA showed a tendency to decrease in groups B and $C$ rabbits, when compared with control group animals (group $\mathrm{A} ; P=0.06$ ).

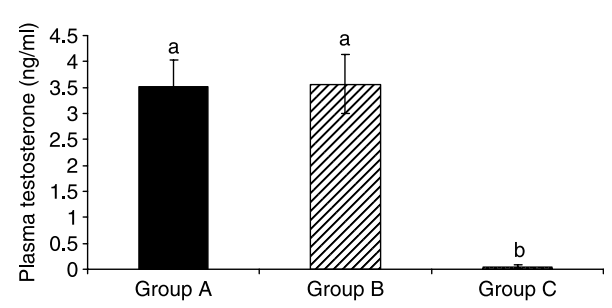

Figure 1 Plasma testosterone in rabbits in group $A$ (control group) and food-restricted groups ( $B$ and $C$ ). Values are expressed as mean \pm S.E.M. Bars with different letters differ significantly $(P<0.001)$. 


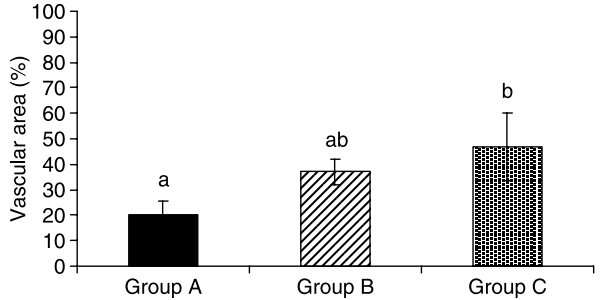

Figure 2 Vascular areas in rabbit testicular tissue in group A (control group) and food-restricted groups (B and $C$ ). Values are expressed as mean \pm S.E.M. Bars with different letters differ significantly $(P<0.05)$.

\section{Discussion}

Changes in nutrition can lead to profound responses in reproductive efficiency (Martin \& Walkden-Brown 1995). In male ruminants, nutritional signals strongly affect the reproductive system; however, the responses are partly independent of changes in gonadotropin secretion (Martin \& Walkden-Brown 1995). The gametogenic tissue responds quickly to changes in nutrition, but the endocrine compartments are less affected (Martin \& Walkden-Brown 1995).

In the present study, seminiferous tubule area and germ cell presence did not change among experimental groups. According to the present results, it appears that food restriction did not induce structural changes in seminiferous tubule morphology. Previous work in Sprague-Dawley rats showed that a severe food restriction and weight reduction to $50-60 \%$ of control animals also did not have any effect on the number of sperm cells in the cauda epididymis and on the number of homogenization resistant spermatids in the testis (Chapin et al. 1993). In addition, the increase in vascular endothelial growth factor (VEGFA) concentration in cultured bovine testis tissue did not affect the percentage of seminiferous tubule cross sections that contained germ cells (Schmidt et al. 2006). Also, in our study, no changes were found among groups in the presence of germ cells and spermatozoa in the seminiferous tubules. Even though germ cells existed in the testes, this does not indicate that spermatozoa production was normal, since no ejaculate was evaluated. However, in the most foodrestricted group (group C), there was an increase in both

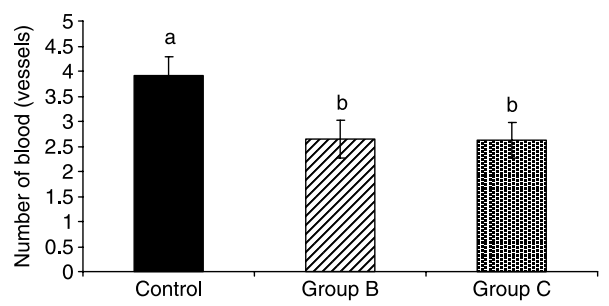

Figure 3 Number of blood vessels per section of rabbit testicular tissue in control group (A) and food-restricted groups (B and C). Values are expressed as mean \pm S.E.M. Bars with different letters differ significantly $(P<0.05)$.

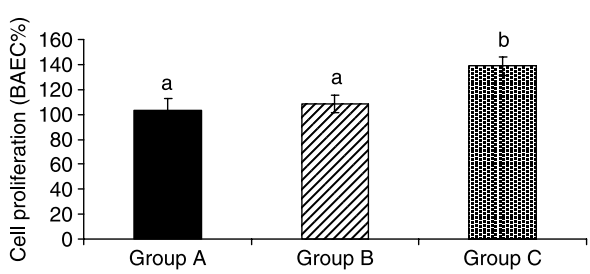

Figure 4 Proliferation stimulation of BAEC in testicular conditioned media in control group (A) and food-restricted groups (groups B and C). Values are expressed as mean \pm S.E.M. Bars with different letters differ significantly $(P<0.05)$.

vascular areas and endothelial cell proliferation induced by angiogenic factors produced by rabbit testes. Nevertheless, it may be difficult to conclude that testicular angiogenesis increase reflects on spermatogenesis.

In the present work, plasma testosterone was significantly decreased only in the food-restricted group C. These results are consistent with the previous studies. In fact, short-term (6 weeks) $40 \%$ caloric restriction resulted in a suppression of in vitro Leydig cell function and serum testosterone in Brown Norway rats, when compared with controls (Chen et al. 2005). In adult rats, a 3-day starvation period caused a decrease in plasma testosterone, even though their Leydig cells were capable of in vitro testosterone production (Grizard et al. 1997). In addition, in growing male rats, caloric restriction decreased circulating testosterone (Chacon et al. 2004). The testosterone decrease observed in the severely food-restricted rabbits in the present study may be ascribed to nutritional impairment.

The decrease in RNA and protein concentration, protein:DNA and RNA:DNA ratios in the testes from restricted fed rabbits reflects the undernutrition imposed on the experimental animals. Even though testicular cells appeared not to undergo any significant decrease in number, as suggested by a similar DNA concentration

Table 2 Concentrations of DNA, RNA, protein, RNA:DNA, and protein:DNA in testicular tissue in control group $(A)$ and food-restricted groups (groups B and C).

\begin{tabular}{lll}
\hline Variable & Group & Mean \pm s.E.M. \\
\hline DNA (mg/g of tissue) & A & $0.95 \pm 0.20$ \\
& B & $1.13 \pm 0.09$ \\
RNA (mg/g of tissue) & C & $1.07 \pm 0.01$ \\
& A & $31.96 \pm 5.77^{\mathrm{a}}$ \\
& B & $20.66 \pm 4.07^{\mathrm{b}}$ \\
Protein (mg/g of tissue) & C & $19.91 \pm 0.68^{\mathrm{b}}$ \\
& A & $57.64 \pm 1.74^{\mathrm{a}}$ \\
RNA:DNA & B & $43.29 \pm 1.25^{\mathrm{b}}$ \\
& C & $36.38 \pm 7.63^{\mathrm{b}, \mathrm{c}}$ \\
Protein:DNA & A & $38.93 \pm 8.30^{\mathrm{a}}$ \\
& B & $18.81 \pm 4.01^{\mathrm{b}}$ \\
& C & $18.59 \pm 0.49^{\mathrm{b}}$ \\
& A & $90.71 \pm 26.70$ \\
& B & $39.46 \pm 4.05$ \\
& C & $40.01 \pm 9.67$
\end{tabular}

Variables with different superscripts differ significantly (a versus b, $P<0.05$; a versus c, $P<0.01$ ). 
among experimental groups, protein synthesis might have been impaired due to undernutrition. Testicular regression has also been reported in white-footed mice (Peromyscus leucopus) in response to receiving $70 \%$ of control intake for 8 weeks (Young et al. 2000). On the contrary, Sprague-Dawley rats receiving $70 \%$ of a control diet showed significant testicular weight gain as compared with control animals (Gursoy et al. 2001). Also in Sprague-Dawley rats, a similar food restriction produced no Leydig cell atrophy, hematological, blood biochemical, and pathological changes, in contrast to males receiving only $55 \%$ of food ad libitum (Seki et al. 1997).

The rabbits that were subjected to the most restricted food intake on this experiment presented an increased testicular microvascular area, in spite of the number of testicular blood vessels being the highest in the animals fed ad libitum. This high number of blood vessels in the testes of control group rabbits, associated with a decrease in vascular areas, might be explained by smaller blood vessels lumen and vessel contraction (Modlich et al. 1996). This increase in testicular microvascular area in the most restricted experimental group was simultaneous with a raise in in vitro endothelial cell mitogenesis, suggesting a higher concentration of angiogenic factors in testicular tissue, even though its physiologic meaning is poorly understood. Since no difference was observed on BAEC proliferation for negative controls, these data show that endothelial cell proliferation did depend on testicular angiogenic activity.

Although angiogenesis has been well studied in developmental and pathological conditions, the role of angiogenic factors in mature blood vessels is not well known. It has been suggested that Leydig cells secrete angiogenic factors (Collin \& Bergh 1996). A study on adult mice supported the concept that VEGFA stabilizes mature vessels in adult tissues, such as the testes (Maharaj et al. 2006). This angiogenic factor was low in quiescent adult testes (Mezquita et al. 1999). However, endothelial cell proliferation was higher in male reproductive organs, such as the testes, than in liver, muscle, and brain (Lissbrant et al. 2003). A continuous turnover of endothelial cells, accompanied by apoptosis of these cells, has been reported in male reproductive organs under normal conditions (Collin \& Bergh 1996). In the prostate, blood vessel endothelial cells are stimulated by locally synthesized androgens to produce paracrine growth factors that can promote the growth of secretory epithelium (Franck-Lissbrant et al. 1998). Testosterone withdrawal decreased endothelial cell proliferation, showing that hormonally regulated endothelial cell proliferation is not unique to female reproductive tract but takes place also in male reproductive organs (Lissbrant et al. 2003). Besides, androgen receptors have been shown in endothelial cells in rat and human prostate (El Alfy et al. 1999, Pelletier et al. 2000). The high proliferation rate in endothelial cells suggests remodeling of the testicular microvasculature (Collin \& Bergh 1996), which might have occurred in the testes of the most food-restricted rabbits (group C), in the present study. Since, in the hamster, increased angiogenesis and rapid renewal of testicular microvasculature is fundamental for physiologic seasonal testicular recrudescence (Mayerhofer et al. 1989), a raise in angiogenesis in the rabbit testes during puberty may be a compensatory mechanism to overcome nutritional impairment. However, since testosterone production appeared to be decreased in the most food restricted rabbits (group C), in which testicular angiogenic activity was the highest, angiogenesis in testes might not only be an androgen-dependent process. Therefore, further studies of novel mechanisms in testicular blood vessel growth and spermatogenesis should be conducted.

\section{Materials and Methods}

\section{Animals}

Fifteen New Zealand white male rabbits (Oryctolagus cuniculus cuniculus) were purchased from a registered breeder (Farmolap, Gafanha da Nazaré, Portugal) at an age of 10-12 weeks. All animals were given an initial adaptation period of 4 weeks to the animal facilities, which were maintained with controlled temperature $\left(20 \pm 2{ }^{\circ} \mathrm{C}\right)$, humidity $(70 \pm 5 \%)$, and photoperiod (12 h light: $12 \mathrm{~h}$ darkness). After, at the age of 1416 weeks, the rabbits were randomly assigned to a control group (A, $n=5)$, fed ad libitum, and to groups B $(n=5)$ and C $(n=5)$, with two different levels of food restriction, for a period of 8 weeks, inducing a weight reduction of 21.1 and $34.7 \%$ in groups B and C respectively. All experimental animals were fed on standard rabbit commercial pellets (Biona 701, Saprogal, Vila Chã de Ourique, Portugal) with the following composition: $14.9 \%$ crude protein, $2.7 \%$ crude fat, $14 \%$ crude fiber, and $13 \%$ ash. Water was given ad libitum to all groups. Both European Union (European Legislation no. 86/609/CEE) and Portuguese regulations and guidelines on care, use, and handling of laboratory animal experimentation were followed. Experiments was monitored by competent veterinary authorities and approved by the ethical committee of the Faculty of Veterinary Medicine (Lisbon, Portugal). Authors L Mateus, S van Harten, and L Alfaro Cardoso are holders of an FELASA (Federation of European Laboratory Animal Science Associations) grade $\mathrm{C}$ certificate, which allows designing and conducting laboratory animal experimentation in the European Union.

\section{Collection and preparation of testicular tissue}

The rabbits were anesthetized and euthanized by inhalation using an overdose of $4 \%$ isoflurane (IsoFlo, Veterinaria Esteve, Bologna, Italy). Testes were collected, the epididymis was removed, and testes were weighed and cut transversally into small pieces, to be used for the different assays. Testicular tissue 
samples for histological studies were immediately placed in $4 \%$ buffered formaldehyde, fixed overnight, and dehydrated in a series of ethanol solutions and embedded in paraffin. Sections were cut $(6 \mu \mathrm{m}$ thick) with a rotatory microtome (Leica RM2125RT; Leica Microsystems Nussloch GmbH, Nussloch, Germany), stained with Periodic Acid Schiff reagent (Sigma), and evaluated under a light microscope (Olympus $\mathrm{CH} 30)$. For DNA, RNA, and protein concentration determination, the tissue was immediately stored at $-80{ }^{\circ} \mathrm{C}$.

For mitogenesis assays, $60 \mathrm{mg}$ testicular tissue were incubated in $2 \mathrm{ml}$ culture medium, for $24 \mathrm{~h}$, in a tissue incubator (Biosafe Eco-Integra Biosciences, Chur, Switzerland; $37{ }^{\circ} \mathrm{C}, 5 \% \mathrm{CO}_{2}, 95 \%$ air) on a shaker (Titertek; Huntsville, $\mathrm{AL}$, USA; $150 \mathrm{rpm})$. The culture medium consisted of DMEM and Ham's F12 (1:1 v/v) supplemented with $0.1 \%$ BSA, penicillin $(100 \mathrm{lU} / \mathrm{ml})$, and streptomycin $(100 \mu \mathrm{g} / \mathrm{ml}$; all reagents from Sigma). Negative controls consisted of culture media with no testicular tissue. After incubation, media were stored at $-70^{\circ} \mathrm{C}$ for mitogenesis assays.

\section{Blood collection and testosterone determination}

While the rabbits were anesthetized, blood samples $(2 \mathrm{ml})$ were collected from the heart into heparinized tubes (MonovettesSarstedt, Numbrecht, Germany) and transported on ice to the laboratory, centrifuged, and stored at $-20^{\circ} \mathrm{C}$. Plasma testosterone was determined using solid-phase RIA (Coat-a-Count Total Testosterone, TKTT1; Siemens Medical Solutions Diagnostics, Los Angeles, CA, USA). Intra-assay coefficient of variation for all samples was 2\%, calculated according to Rodbard (1974).

\section{Determination of DNA, RNA, and protein concentration}

To assess testicular DNA concentration, $100 \mathrm{mg}$ testicular tissue were minced and homogenized with a polytron (Ultraturrax T8, IKA-Werke, Staufen, Germany) in $1.2 \mathrm{ml}$ digestion buffer $(100 \mathrm{nM} \mathrm{NaCl}, 10 \mathrm{mM}$ Tris-Cl (pH 8), 25 mM EDTA (pH 8), $0.5 \%$ SDS, $0.1 \mathrm{mg} / \mathrm{ml}$ proteinase $\mathrm{K}$ ) and was kept at $4{ }^{\circ} \mathrm{C}$. The digest was deproteinized by successive phenol/chloroform/isoamyl alcohol extractions, recovered by ethanol precipitation, dried, and resuspended in buffer as described elsewhere (Ausubel et al. 1992). Finally, DNA quantification was determined using a UV photometer (Ultrospec 3100 pro; Amersham Biosciences) at a wavelength of $260 \mathrm{~nm}$.

For RNA determination, $100 \mathrm{mg}$ testicular tissue were ground and homogenized in Trizol reagent followed by the addition of chloroform. This separates the solution in two phases with RNA remaining on the top, in the aqueous phase. The RNA was recovered by precipitation with isopropyl alcohol and quantified in a UV spectrophotometer at $260 \mathrm{~nm}$ (Chomczynski \& Mackey 1995).

Determination of protein concentration was performed on sample homogenates by using the Coomassie Plus protein assay (Pierce Chemical Co., Rockford, IL, USA). BSA was used as standard. Tissue hyperplasia is indicated by cell concentration of DNA while ratios of RNA:DNA and protein:DNA are considered to be an index of tissue hypertrophy (Baserga 1985, Reynolds et al. 1992).

\section{Morphologic assessment and microvascular density evaluation}

Microscopic slides were observed by light microscope (Olympus CK40, Wetzlar-Nauborn, Germany) in order to identify any pathological changes. Since no clinical, gross, or microscopic changes were observed, morphological assessment and microvascular density evaluation were performed. For each animal, 28 randomly selected fields were photographed using a light microscope at $1000 \times$ magnification. The total percentage area occupied by seminiferous tubules as well as percentage of seminiferous tubules filled with all stages of spermatogenesis (spermatogonia, spermatocytes, and spermatids) and spermatozoa were calculated. In the same histological fields, testicular vascular areas were measured by using computerized image analysis (Scion Image, NIH, USA). No distinction was made among arterioles, venules, or capillaries. Vascular density was assessed as the percentage of the area occupied by blood vessels with respect to the entire area of each micrograph (Ferreira-Dias et al. 2001, 2006). For each animal, vascular area was considered as the mean value of the area of blood vessels assessed for that animal (Ferreira-Dias et al. 2006). The mean number of testicular blood vessels was also evaluated for each animal, on the same 28 randomly selected fields used for vascular area determinations.

\section{Mitogenesis assays}

The ability of media conditioned by testicular tissue to stimulate mitogenesis of BAEC was studied utilizing the same exact cells and passage number provided by and described by Redmer et al. (1988). Briefly, these BAEC $\left(2 \times 10^{4}\right.$ cells $\left./ \mathrm{ml}\right)$ were allowed to attach to the bottom of a 24-well culture plate (Nucleon-Nunc, Ballerup, Denmark) for $24 \mathrm{~h}$, in a tissue incubator (Biosafe EcoIntegra Biosciences; $37^{\circ} \mathrm{C}, 5 \% \mathrm{CO}_{2}, 95 \%$ air; Ferreira-Dias et al. 2006). Samples of testicular conditioned media were added in triplicate wells at a final concentration of $30 \% \quad(30 \%$ conditioned media by the samples $+70 \%$ DMEM), and incubated for another $72 \mathrm{~h}$. Afterward, in order to assess BAEC proliferative response, the number of these cells in each well was determined using a Neubauer chamber under the light microscope (Olympus CK40), and further compared with negative controls (with no testicular tissue). The percentage of BAEC proliferation in media conditioned by testes was calculated with respect to negative controls, which were considered $100 \%$ of cell mitogenesis (Ferreira-Dias et al. 2006).

\section{Statistical analysis}

Statistical significance of (i) testicular weight; (ii) testicular area occupied by seminiferous tubules; (iii) seminiferous tubules containing all stages of spermatogenesis and spermatozoa; (iv) plasma testosterone concentration; (v) testicular microvascular density evaluation; (vi) endothelial cells mitogenesis; and (vii) DNA, RNA, and protein concentration, RNA:DNA, and protein:DNA among groups were analyzed by one-way 
ANOVA. The level of significance was set at $P<0.05$. Whenever a significant difference was detected, a Bonferroni multiple comparison test (GraphPAD PRISM Version 4.00, San Diego, CA, USA) was performed.

\section{Declaration of interest}

We do declare that there is no conflict of interest which could be perceived as prejudicing the impartiality of the research reported.

\section{Funding}

This work was supported by Centro de Investigação Interdisciplinar em Sanidade Animal (CIISA), Portugal (grant CIISA 75/Angiogénese-Apoptose); and Sofia Van Harten is a PhD student supported Fundação para a Ciência e Tecnologia (FCT), Portugal (grant SFRH/BD/4943/2001).

\section{Acknowledgements}

The authors wish to thank Dr Paula Serrão for technical assistance.

\section{References}

Augustin HG, Braun K, Telemenakis I, Modlich U \& Kuhn W 1995 Phenotypic characterization of endothelial cells in a physiological model of blood vessel growth and regression. American Journal of Pathology 147 339-351.

Ausubel FM, Brent R, Kingston RE, Moore DD, Seidman JD, Smith JA \& Struhl K 1992 Preparation and analysis of DNA. In Short Protocols in Molecular Biology, 2nd edn, pp 2-38. New York: J Wiley \& Sons.

Baserga R 1985 Tissue growth. In The Biology of Cell Reproduction, 1 edn, pp 46-58. Ed. R Baserga. Cambridge: Harvard University Press.

Beecken WDC, Fernandez A, Joussen AM, Achilles EG, Flynn E, Lo KM, Gillies SD, Javaherian K, Folkman J \& Shing Y 2001 Effect of antiangiogenic therapy on slowly growing, poorly vascularized tumors in mice. Journal of the National Cancer Institute 93 382-387.

Birt DF, Yaktine A \& Duysen E 1999 Glucocorticoid mediation of dietary energy restriction inhibition of mouse skin carcinogenesis. Journal of Nutrition 129 571-574.

Bronson FH 1999 Puberty and energy reserves: a walk on the wild side. In Reproduction in Context, 1 edn, pp 15-33. Eds K Wallen \& JS Schnider. Cambridge: MIT Press.

Chacon F, Cano P, Jimenez V, Cardinali DP, Marcos A \& Esquifino AI 2004 24-Hour changes in circulating prolactin, follicle-stimulating hormone, luteinizing hormone, and testosterone in young male rats subjected to caloric restriction. Chronobiology International 21 393-404.

Chapin RE, Gulati DK, Barnes LH \& Teague JL 1993 The effects of feed restriction on reproductive function in Sprague-Dawley rats. Toxicological Sciences 20 23-29.

Chavakis E \& Dimmeler S 2002 Regulation of endothelial cell survival and apoptosis during angiogenesis. Arteriosclerosis, Thrombosis, and Vascular Biology 22 887-893.

Chen H, Luo L, Liu J, Brown T \& Zirkin BR 2005 Aging and caloric restriction: effects on Leydig cell steroidogenesis. Experimental Gerontology 40 498-505.

Chomczynski P \& Mackey K 1995 Short technical report. Modification of the TRIZOL reagent procedure for isolation of RNA from polysaccharide and proteoglycan-rich sources. BioTechniques 19 942-945.

Collin O \& Bergh A 1996 Leydig cells secrete factors which increase vascular permeability and endothelial cell proliferation. International Journal of Andrology 19 221-228.
El Alfy M, Luu-The V, Huang XF, Berger L, Labrie F \& Pelletier G 1999 Localization of type 5 17beta-hydroysteroid dehydrogenase, 3betahydroysteroid dehydrogenase, and androgen receptor in the human prostate by in situ hybridization and immunocytochemistry. Endocrinology 140 1481-1491.

Espinosa Cervantes MC \& Rosado Garcia A 2002 Angiogenesis in reproductive physiology. Follicular development, formation and maintenance of the corpus luteum. Ginecología y Obstetricia de México $7017-27$.

Ferreira-Dias G, Serrão PM, Costa Durão J \& Robalo Silva J 2001 Microvascular development and growth of the uterus during the estrous cycle in the mare. American Journal of Veterinary Research $\mathbf{6 2}$ 526-530.

Ferreira-Dias G, Pinto Bravo P, Mateus L, Redmer D \& Medeiros JA 2006 Microvascularization and angiogenic activity of equine corpora lutea throughout the estrous cycle. Domestic Animal Endocrinology 30 247-259.

Folkman J \& Klagsburn M 1987 Angiogenic factors. Science 235 442-447.

Franck-Lissbrant I, Häggström S, Damber JE \& Bergh A 1998 Testosterone stimulates angiogenesis and vascular regrowth in the ventral prostate in castrated adult rats. Endocrinology 139 451-456.

Grizard G, Artonne C, Grizard J \& Boucher D 1997 Effect of short-term starvation on Leydig cell function in adult rats. Archives of Andrology 38 207-214.

Gursoy E, Cardounel A, Hu Y \& Kalimi M 2001 Biological effects of longterm caloric restriction: adaptation with simultaneous administration of caloric stress plus repeated immobilization stress in rats. Experimental Biology and Medicine 226 97-102.

Hazzard TM, Rohan RM, Molskness TA, Fanton JW, Dámato RJ \& Stouffer RL 2002 Injection of antiangiogenic agents into the macaque preovulatory follicle: disruption of corpus luteum development and function. Endocrine 17 199-206.

Hudlicka O 1984 Development of microcirculation: capillary growth and adaptation. In Section 2: The Cardiovascular System, Part 1: Microcirculation, 1 edn, vol IV, pp 165-216. Eds EM Renkin \& CC Michael. Washington, DC: American Physiological Society.

Ishiko O, Sumi T, Yoshida H, Hyun Y \& Ogita S 2001 Comparison of expression of apoptosis regulatory proteins in the adipose tissue of tumorbearing and diet-restricted rabbits. International Journal of Molecular Medicine 8 543-547.

Koubova J \& Guarente L 2003 How does calorie restriction work? Genes and Development 17 313-321.

Lissbrant IF, Lissbrant E, Persson A, Damber JE \& Bergh A 2003 Endothelial cell proliferation in male reproductive organs of adult rat is high and regulated by testicular factors. Biology of Reproduction 68 1107-1111.

Maharaj AS, Saint-Geniez M, Maldonado AE \& D'Amore PA 2006 Vascular endothelial growth factor localization in the adult. American Journal of Pathology 168 639-648.

Martin GB \& Walkden-Brown SW 1995 Nutritional influences on reproduction in mature male sheep and goats. Journal of Reproduction and Fertility 49 437-449.

Mayerhofer A, Sinha Hikim AP, Bartke A \& Russell LD 1989 Changes in the testicular microvasculature during photoperiod-related seasonal transition from reproductive quiescence to reproductive activity in the adult golden hamster. Anatomical Record 224 495-507.

McCarter R, Masoro EJ \& Yu BP 1985 Does food restriction retard aging by reducing the metabolic rate? American Journal of Physiology $\mathbf{2 4 8}$ E488-E490.

Mezquita J, Mezquita B, Pau M \& Mezquita C 1999 Characterization of a novel form of angiopoietin-2 (Ang-2B) and expression of VEGF and angiopoietin-2 during chicken testicular development and regression. Biochemical and Biophysical Research Communications $260492-498$.

Modlich U, Kaup F-J \& Augustin H 1996 Cyclic angiogenesis and blood vessel regression in the ovary: blood vessel regression during luteolysis involved endothelial cell detachment and vessel occlusion. Laboratory Investigation 74 771-780.

Morimura M, Ishiko O, Sumi T, Yoshida H \& Ogita S 2001 Angiogenesis in adipose tissues and skeletal muscles with rebound weight-gain after dietrestriction in rabbits. International Journal of Molecular Medicine 8 499-503. 
Mukherjee P, El-Abbadi MM, Kasperzyk JL, Ranes MK \& Seyfried TN 2002 Dietary restriction reduces angiogenesis and growth in an orthotopic mouse brain tumour model. British Journal of Cancer 86 1615-1621.

Mukherjee P, Abate LE \& Seyfried TN 2004 Antiangiogenic and proapoptotic effects of dietary restriction on experimental mouse and human brain tumors. Clinical Cancer Research 10 5622-5629.

Pelletier G, Labrie C \& Labrie F 2000 Localization of oestrogen receptor alpha, oestrogen receptor beta and androgen receptor in the rat reprodcutive organs. Journal of Endocrinology 165 359-370.

Redmer DA, Grazul AT, Kirsch DJ \& Reynolds LP 1988 Angiogenic activity of bovine corpora lutea at several stages of luteal development. Journal of Reproduction and Fertility 82 627-634.

Reynolds LP, Killilea SD \& Redmer DA 1992 Angiogenesis in the female reproductive tract. FASEB Journal 6 886-892.

Roberto da Costa RP, Ferreira-Dias G, Mateus L, Korzekwa A Andronowska A, Platek R \& Skarzynski DJ 2007 Endometrial nitric oxide production and nitric oxide synthases in the equine endometrium: relationship with microvascular density during the estrous cycle. Domestic Animal Endocrinology 32 287-302.

Rodbard D 1974 Statistical quality control and routine data processing for radioimmunoassay and immunoradiometric assays. Clinical Chemistry 20 1255-1270.
Santos AM, Ferraz MR, Teixeira CV, Sampaio FJ \& Ramos CF 2004 Effects of undernutrition on serum and testicular testosterone levels and sexual function in adult rats. Hormone and Metabolic Research 36 27-33.

Schmidt JA, de Avila JM \& McLean DJ 2006 Effect of vascular endothelial growth factor and testis tissue culture on spermatogenesis in bovine ectopic testis tissue xenographs. Biology of Reproduction 75 167-175.

Seki M, Yamaguchi K, Marumo H \& Imai K 1997 Effects of food restriction on reporductive and toxicological parameters in rats - in search of suitable feeding regímen in long-term tests. Journal of Toxicological Science 22 427-437.

Thwaites CJ 1995 Effect of undernutrition on the size and tone of the ram's testes. Small Ruminant Research 16 283-286.

Young KA, Zirkin BR \& Nelson RJ 2000 Testicular regression in response to food restriction and short photoperiod in white-footed mice (Peromyscus leucopus) is mediated by apoptosis. Biology of Reproduction 62 347-354.

Received 9 May 2008

First decision 25 June 2008

Revised manuscript received 3 December 2008

Accepted 9 December 2008 